\title{
Foreign Language Anxiety and Strategy Use: A Study with Chinese Undergraduate EFL Learners
}

\author{
Zhongshe Lu \\ Tsinghua University, China \\ Email: lvzhs@tsinghua.edu.cn \\ Meihua Liu \\ Tsinghua University, China \\ Email: ellenlmh@gmail.com
}

\begin{abstract}
The present study explored foreign language anxiety and strategy use in relation to their interactive effect on the students' performance in English. The participants were 934 Chinese undergraduates who completed a 71-item survey. Complicated statistical analyses (e.g., correlation analyses, regression analyses and structural equaling model) were run on the data, which show that 1) nearly one-third of the students experienced anxiety in English class, 2) the participants mainly reported a medium use of both cognitive and metacognitive strategies, 3) foreign language classroom anxiety, cognitive strategy use, and metacognitive strategy use were all significantly correlated with one another, and 4) all the measured variables produced a significant effect on the students' performance in English. Based on the findings, some implications for teaching and learning of English are discussed.
\end{abstract}

Index Terms - anxiety, cognitive, metacognitive, strategy use, performance

\section{INTRODUCTION}

Extensive research has explored anxiety or language learning strategy use among learners of English as a second/foreign language (SL/FL) and students of various backgrounds learning other languages such as Japanese, Spanish and Russian (Gu \& Johnson, 1996; O’Malley \& Chamot, 1990; Oxford, 1990; Zhang \& Liu, 2008). However, not much research can be found on anxiety and language learning strategy use simultaneously in the same SL/FL context. The present research examined foreign language anxiety and strategy use in relation to their interactive effect on the students' performance in English simultaneously with Chinese university EFL learners of similar backgrounds.

\section{LITERATURE REVIEW}

Over the decades, research on anxiety and language learning strategy use has been flourishing. Based on quantitative and/or qualitative data, researchers have generally found that many students experience anxiety in language classes, that anxiety is predominantly inversely correlated with language performance, that more proficient students are less anxious, that anxious students can be identified, and that anxiety is closely related to many other linguistic, cognitive, and affective factors such as learning style, learning strategy, unwillingness to communicate, competition, and motivation (Argaman \& Abu-Rabia, 2002; Bailey, 1983; Chen, 2002; Cheng, Horwitz, \& Schallert, 1999; Ehrman \& Oxford, 1995; Gregersen \& Horwitz, 2002; Liu, 2006, 2007; Phillips, 1992; Saito, Horwitz, \& Garza, 1999; Yan \& Horwitz, 2008). As interviews, observations and reflective journals are frequently used in qualitative studies, the predominantly employed instrument in quantitative studies to measure foreign language anxiety is the Foreign Language Classroom Anxiety Scale developed by Horwitz, Horwitz and Cope (1986). The scale, often abbreviated as the FLCAS was designed to measure three dimensions of foreign language classroom anxiety: communication apprehension, test anxiety, and fear of negative evaluation (Horwitz et al., 1986). Communication apprehension originates from the fear of or anxiety about communicating with people; fear of negative evaluation refers to the apprehension about others' evaluations; and test anxiety stems from a fear of failure in tests (Horwitz et al., 1986).

Likewise, numerous studies on language learning strategy use have exposed that it is closely related to learning outcomes in that more successful language learners tend to use more good language learning strategies and choose the strategies more appropriate to a certain language task (Abraham \& Vann, 1987; Bremner, 1999; Gu \& Johnson, 1996; Naiman, Frø̋hlich, Stern \& Todesco, 1978; Rubin, 1975; Vandergrift, 1996, 1997; Wang, 2007; Wen, 1995, 1996; Zhang \& Liu, 2008), and that it interacts with various other variables to affect language learning such as motivation, cultural background, task type, age, L2 proficiency, learning style, and gender (Grainger, 1997; Oxford, 1989; Oxford \& Nyikos, 1989; Skehan, 1989; Vandergrift, 1996, 1997). And the most often employed baseline model to measure learners' language strategy use is the Strategy Inventory for Language Learning developed by Oxford (1990). According to this Inventory, language learning strategies fall into six categories: memory, cognitive, metacognitive, compensation, 
affective, and social strategies. Memory strategies are concerned with the storing and retrieval of information; cognitive strategies refer to the manipulation or transformation of the target language by the learner; compensation strategies enable learners to use the target language for either compensation or production in spite of limitations in knowledge of the language; metacognitive strategies relate to learners' cognition; affective strategies involve the regulation of feelings and attitudes; and social strategies involve communication with other people, acknowledging the fact that language is a form of social behavior (Oxford, 1990).

The use of cognitive and metacognitive strategies has been frequently the focus in a number of studies (Chamot $\&$ El-Dinary, 1999; Chamot \& Küpper, 1989; O’Malley, Chamot, Stewner-Manzares, Kupper \& Russo, 1985; Purpura, 1997; Vandergrift, 1997, 2003; Wen, 1995), which have revealed that more proficient learners tend to use cognitive and metacognitive strategies more, and that metacognitive strategy use and cognitive strategy use often interact with each other to affect students' performance in the target language. Likewise, foreign language anxiety, as reviewed above, has been uncovered to be an important debilitating factor in the learning of a SL/FL language. The present study aimed to explore the relationship between foreign language classroom anxiety and the use of cognitive and metacognitive strategies in relation to their interactive effect on students' performance in English in Chinese university EFL contexts. For this purpose, the following research questions were formulated:

1) What is the general pattern of foreign language classroom anxiety in Chinese university EFL learners?

2) What is the broad profile of cognitive and metacognitive strategy use by the Chinese university EFL learners?

3) How is the students' foreign language classroom anxiety related to their use of cognitive and metacognitive strategies?

4) How do the measured variables correlate with the students' performance in English?

\section{RESEARCH DESIGN}

\section{A. Participants}

The participants were 934 (587 male and 347 female) first-year non-English majors from various disciplines such as Law, Engineering, Mechanics and Economics and Management at three universities in China. All were enrolled in credit-bearing and compulsory English courses offered by their universities. With an age range from 13 (only one extremely excellent student) to 21 and an average age of 18.49 , the majority $(451 / 48.3 \%$ ) of the participants aged 18 , followed by the group aged 19 (315/33.7\%), and then came the groups aged $20(97 / 10.4 \%)$ and $17(53 / 5.7 \%)$.

\section{B. Instrument}

For this study, the students completed a survey consisting of a 19-item Cognitive Strategy Use Questionnaire, a 16-item Metacognitive Strategy Use Questionnaire, a 36-item Foreign Language Classroom Anxiety Scale, and the background questionnaire, as detailed below. The strategy use questionnaire items were placed on a 5-point Likert scale ranging from 'Always or almost always used' to 'Never or almost never used' with values 1-5 assigned to the descriptors respectively. Also placed on a 5-point Likert scale, the descriptors for the anxiety questionnaire items ranged from 'Strongly disagree' to 'Strongly agree'.

In the present study, both the Cognitive Strategy Use Questionnaire (CSUQ) and the Metacognitive Strategy Use Questionnaire (MSUQ) were adapted from the Strategy Inventory for Language Learning developed by Oxford (1990). To better fit the present situation, five more items were added to the CSUQ and seven more items to the MSUQ respectively, with reference to the English Learning Strategy Use Questionnaire self-developed by Liu and Zhang (2010).

The Cognitive Strategy Use Questionnaire (CSUQ). With Oxford's (1990) classification as the base model, this 19-item CSUQ ( $a=.819$ ) intended to measure four dimensions of cognitive strategy use: practicing (CSUQ1) (e.g., I listen to/watch an English episode repeatedly until I understand every word.), comprising 6 items, receiving and sending messages (CSUQ2) (e.g., I read for pleasure in English.) having 3 items, analyzing and reasoning consisting of 7 items (CSUQ3) (e.g., I try to find patterns in English.), and creating structure for input and output having 3 items (CSUQ4) (e.g., I write notes, messages, letters, or reports in English.).

The Metacognitive Strategy Use Questionnaire (MSUQ). This 16-item MSUQ ( $a=.8796)$ sought to measure three dimensions of metacognitive strategy use: centering one's learning (MSUQ1) (e.g., I pay attention when someone is speaking English.) which includes 4 items, arranging and planning (MSUQ2) (e.g., I have clear goals for improving my English skills.) which has 8 items and evaluating one's learning (MSUQ3) (e.g., I test myself on English materials.) consisting of 4 items.

The Foreign Language Classroom Anxiety Scale (FLCAS). This 36-item FLCAS $(\mathrm{a}=.92)$ was directly adopted from that in Liu's $(2006,2007)$ and Liu and Jackson's (2008) studies which was adapted from the scale developed by Horwitz et al. (1986) to the better suit the Chinese EFL context. As theorized by Horwitz et al. (1986), the FLCAS intended to measure three dimensions of foreign language classroom anxiety: fear of negative evaluation (FLCAS1) (e.g., I tremble when I know that I'm going to be called on in the English class.) comprising 12 items which were reflective of fear of being negatively evaluated, communication apprehension (FLCAS2) (e.g., I would not be nervous speaking English with native speakers.) consisting of 7 items which indicated apprehension of speech communication, and test anxiety (FLCAS3) (e.g., I am usually at ease during English tests in my class.) having 2 items suggestive of 
fear of English tests.

Background information. The background questionnaire aimed to gather the respondents' demographic information such as name, gender, department, university, and English-learning time.

Performance in English. All the participants' scores in the course final exam taken in the last $\left(16^{\text {th }}\right)$ week of the term were collected as their performance in English (Liu, 2006). The exam consisted of listening, reading and writing (speaking was excluded because it was time-consuming), but only the total score was used in the present study.

\section{Procedure}

The survey was administered to 30 intact classes of first-year undergraduate non-English majors at three universities in the $14^{\text {th }}$ week of the first 16-week term of Academic Year 2007-2008. The survey was competed in about 13 minutes. Of 1121 collected questionnaires, 934 were complete for further statistical analyses.

\section{Data Analysis}

For each measure, the mean, standard deviation, median, mode, and score range were calculated to determine to what extent the students felt anxious in English language classrooms and/or how frequently they used the strategies when learning English. Then, correlational analyses, regression analyses and structural equation modeling were run to explore the relationship between foreign language anxiety, strategy use, and their predictive effect on the students' performance in English.

\section{RESULTS AND DISCUSSION}

\section{A. Broad Profile of Foreign Language Classroom Anxiety}

To investigate the broad profile of the students' foreign language classroom anxiety, the means, standard deviations, medians, modes, and score ranges of the FLCAS and its three subscales were computed. Thus, the total score of the FLCAS revealed a respondent's anxiety during English language classrooms; the total score of the FLCAS1 represented the respondent's fear of being negatively evaluated; the total score of the FLCAS2 implied anxiety about speech communication; the total score of the FLCAS3 indicated anxiety about English tests. For all the constructs, the higher the score, the more anxious/nervous the respondent felt.

Since there are 36 items on the FLCAS, a total score of more than 144 implies that the respondent is very anxious in oral English classrooms. A total score of 108 to 144 signifies moderate anxiety and a total score of less than 108 indicates no/little anxiety in the oral English classroom. Within the FLCAS construct, the FLCAS1 has 12 items, the FLCAS2 has 7 items, and the FLCAS 3 has 2 items. Therefore, a total score of more than 68 on the FLCAS1 implies strong fear of being negatively evaluated, a total score of 36-68 indicates moderate fear of being negatively evaluated, and a total score of less than 36 reflects no/little fear of being negatively evaluated. As to the FLCAS2, the score ranges for being strongly, moderately apprehensive and strongly/moderately not apprehensive of speech communication are more than 28, 21-28 and less than 21 respectively. And the score ranges for high, moderate and low test anxiety are more than 8, 6-8 and less than 6 respectively. The results are presented in Table 1.

TABLE 1:

STATISTICAL ANALYSES OF THE FLCAS AND ITS SUBSCALES (N = 934)

\begin{tabular}{|l|l|l|l|l|l|l|l|}
\hline & Mean & Standard deviation & Median & Mode & Range & Skewness & Kurtosis \\
\hline FLCAS & 100.07 & 18.75 & 100 & 89 & $36-172$ & -.037 & .378 \\
\hline FLCAS1 & 33.61 & 6.899 & 34 & 36 & $12-59$ & -.077 & -.012 \\
\hline FLCAS2 & 19.98 & 4.38 & 20 & 20 & $7-35$ & -.018 & .126 \\
\hline FLCAS3 & 5.49 & 1.597 & 6 & 6 & $2-10$ & .166 & -.251 \\
\hline
\end{tabular}

With a range of 36 to 172 , the FLCAS had a mean of $100.07(\mathrm{SD}=18.75)$, a median of 100 and mode of 89 , which were all below the scale midpoint 108, implying that approximately one-third of the students experienced anxiety in English class, as found in several existing studies with students of a similar background (Chen, 2002; Liu, 2006, 2007; Wang, 2003).

As shown in Table 1, the FLCAS1 had a mean of 33.61 with a median of 34 and a mode of 36; the FLCAS2 achieved a mean of 19.98 with a median and mode of 20; and the FLCAS3 had a mean of 5.49 with a median and a mode of 6 . Namely, all the subscale scores barely exceeded their scale midpoints $(36,21$, and 6 for the FLCAS1, the FLCAS2, and the FLCAS3, respectively). This lends further support to the result of the FLCAS data that nearly a third of the respondents felt anxious in English class, feared being negatively evaluated, and were apprehensive about both speaking and tests, as found in Liu and Jackson's (2008) study and many others in various contexts (Gardner \& MacIntyre, 1992; Horwitz et al., 1986; Horwitz, 2001; Liu, 2006, 2007).

Moreover, both the skewness and kurtosis values for all the scales were far below 1, implying that a normal distribution existed for all the scales. This further confirms the findings described above.

\section{B. Broad Profile of Cognitive and Metacognitive Strategy Use}

To reveal the broad profile of cognitive and metacognitive strategy use, the means, standard deviations, medians, modes, and the score ranges of the CSUQ, the MSUQ and their subscales were computed. The total score of the 
CSUQ/MSUQ revealed a respondent's use range of cognitive/metacognitive strategies. The higher the score, the more frequently the respondent reportedly used the strategies.

For the 19-item CSUQ, a total score of more than 76 implied a high use of the cognitive strategies in English learning, a total score of 57 to 76 signified a medium use, and a total score of less than 57 indicated a low use. Similarly, a total score of more than 24 for the 6-item CSUQ1 suggested a high use of practicing, a total score of 18 to 24 indicated a medium use, and a total score of less than 18 reflected a low use. For the 3-item CSUQ2 and CSUQ4, the score ranges for a high, medium and low use of receiving and sending messages (CSUQ2) and creating structure for input and output (CSUQ4) respectively were: more than 12,9-12, and less than 9. The score ranges for a high, medium and low use of analyzing and reasoning for the 7-item CSUQ3 were: more than 28, 21-28 and less than 21 respectively. The results are summarized in Table 2.

Likewise, a total score of more than 64 on the 16-item MSUQ suggested a high use of the metacognitive strategies in English learning, a total score of 48 to 64 signified a medium use, and a total score of less than 48 indicated a low use. For the 4-item MSUQ1/MSUQ3, a total score of more than 16 indicated a high use of centering one's attention/evaluating one's learning, a total score of 12 to 16 was implicative of a medium use, and a total score of less than 12 reflected a low use. For the 8-item MSUQ2, the score ranges for a high, medium and low use of arranging and planning one's learning respectively were: more than 32, 24-32, and less than 24 . The results are reported in Table 2.

TABLE 2:

Statistical ANalyses of the Cognitive AND MetaCognitive StRategy Use Questionnaires ( $\mathrm{N}=934$ )

\begin{tabular}{|l|l|l|l|l|l|}
\hline & Frequency of strategy use & Standard deviation & Median & Mode & Score range \\
\cline { 2 - 6 } & Mean/use range & 3.89 & 18 & 18 & $6-30$ \\
\hline CSUQ1 & $17.94 /$ low use & 2.14 & 10 & 10 & $3-15$ \\
\hline CSUQ2 & $9.58 /$ medium use & 3.94 & 22 & 21 & $7-35$ \\
\hline CSUQ3 & $22.4 /$ medium use & 2.13 & 8 & 8 & $3-15$ \\
\hline CSUQ4 & $8.25 /$ low use & 9.21 & 58 & 60 & $20-95$ \\
\hline CSUQ & $58.17 /$ medium use & 2.55 & 15 & 16 & $4-20$ \\
\hline MSUQ1 & $14.38 /$ medium use & 5.16 & 24 & 24 & $8-40$ \\
\hline MSUQ2 & $24.12 /$ medium use & 2.68 & 13 & 12 & $4-20$ \\
\hline MSUQ3 & $12.82 /$ medium use & 8.78 & 51 & 50 & $16-80$ \\
\hline MSUQ & $51.32 /$ medium use & & & & \\
\hline
\end{tabular}

Table 2 shows that the CSUQ achieved a mean of 58.17 (SD =9.21), a median of 58 and a mode of 60 , all (nearly) exceeding the scale midpoint 57 but fell below 76. This suggests a medium use of the cognitive strategies by the participants in English learning. The CSUQ1 had a mean of 17.94, a median and mode of 18, almost all slightly below the scale midpoint 18 , indicating a low use to the upper end of practicing strategies. The CSUQ2 had a mean of 9.58, a median and mode of 10; the CSUQ3 mean was 22.4, with a median of 22 and a mode of 21 . Apparently, both CSUQ 2 and CSUQ 3 scores exceeded their scale midpoints 9 and 21 respectively. Alternatively, the participants had a medium use of the cognitive strategies of receiving and sending messages, and analyzing and reasoning. The mean for the CUSQ4 was 8.25, with a median and mode of 8 , implicative of a low use of the strategies of creating structure for input and output. These findings further confirm the result of the CSUQ data, partially confirming the results of Purpura's (1997) and Zhang and Liu's (2008) studies about the use of cognitive and metacognitive strategies in English tests.

Meanwhile, the MSUQ had a mean of 51.32 ( $\mathrm{SD}=8.78$ ), a median of 51 and a mode of 50 , all being far greater than the scale midpoint 48 but smaller than 64. This implies a medium use of the metacognitive strategies by the correspondents in English learning. In addition, the MSUQ1 had a mean of 14.38, a median of 15 and a mode of 16; the MSUQ2 had a mean of 24.12, a median and mode of 24; and the MSUQ3 mean was 12.82, with a median of 13 and a mode of 12. Clearly, nearly all the MSUQ subscale scores (slightly) exceeded their scale midpoints (12, 24 and 12 for MSUQ1, MSUQ2 and MSUQ 3 respectively). Apparently, the learners reported having a medium use of the strategies of centering attention and evaluating learning, a low but a medium use of the strategies of arranging and planning, as found about the participants during an English test in Purpura's (1997) and Zhang and Liu's (2008) studies.

\section{Relationship between Anxiety and Strategy Use and Performance in English}

To determine the relationship between foreign language anxiety, the use of cognitive and metacognitive strategies, and the students' performance in English, correlational analyses were conducted. The results are presented in Table 3. 
TABLE 3:

CORRELATIONS AMONG THE MEASURED VARIABLES

\begin{tabular}{|c|c|c|c|c|c|c|c|c|c|c|c|c|c|c|}
\hline & $\begin{array}{l}\text { FLC } \\
\text { AS1 }\end{array}$ & $\begin{array}{l}\text { FLC } \\
\text { AS2 }\end{array}$ & $\begin{array}{l}\text { FLC } \\
\text { AS3 }\end{array}$ & $\begin{array}{l}\text { FLC } \\
\text { AS }\end{array}$ & $\begin{array}{l}\text { CSUQ } \\
1\end{array}$ & $\begin{array}{l}\text { CS2 } \\
2\end{array}$ & $\begin{array}{l}\text { CS3 } \\
2\end{array}$ & $\begin{array}{l}\text { CS4 } \\
2\end{array}$ & CS2 & $\begin{array}{l}\text { MSU } \\
\text { Q1 }\end{array}$ & $\begin{array}{l}\text { MSU } \\
\text { Q2 }\end{array}$ & $\begin{array}{l}\text { MSU } \\
\text { Q3 }\end{array}$ & $\begin{array}{l}\text { MSU } \\
Q\end{array}$ & Performance \\
\hline $\begin{array}{l}\text { FLCA } \\
\text { S1 }\end{array}$ & 1 & $\begin{array}{l}.737 \\
* *\end{array}$ & $\begin{array}{l}.513 \\
* *\end{array}$ & $\begin{array}{l}.925 \\
* *\end{array}$ & $\begin{array}{l}-.306^{*} \\
*\end{array}$ & $\begin{array}{l}-358 \\
* *\end{array}$ & $\begin{array}{l}.214 \\
* * \\
\text { * }\end{array}$ & $\begin{array}{l}-.185 \\
* *\end{array}$ & $\begin{array}{l}-.347 \\
* *\end{array}$ & $\begin{array}{l}-.237 \\
* * \\
\end{array}$ & $\begin{array}{l}-.355 \\
* *\end{array}$ & $\begin{array}{l}-.325 \\
* *\end{array}$ & $\begin{array}{l}-376 \\
* *\end{array}$ & $-.260 *$ \\
\hline $\begin{array}{l}\text { FLCA } \\
\text { S2 }\end{array}$ & & 1 & $\begin{array}{l}.473 \\
* *\end{array}$ & $\begin{array}{l}.861 \\
* *\end{array}$ & $\begin{array}{l}-.388^{*} \\
*\end{array}$ & $\begin{array}{l}-.401 \\
* *\end{array}$ & $\begin{array}{l}-.249 \\
* *\end{array}$ & $\begin{array}{l}.190 \\
* *\end{array}$ & $\begin{array}{l}-.408 \\
* *\end{array}$ & $\begin{array}{l}-.269 \\
* *\end{array}$ & $\begin{array}{l}-360 \\
* *\end{array}$ & $\begin{array}{l}-.318 \\
* *\end{array}$ & $\begin{array}{l}-.386 \\
* *\end{array}$ & $-.259^{*}$ \\
\hline $\begin{array}{l}\text { FLCA } \\
\text { S3 }\end{array}$ & & & 1 & $\begin{array}{l}.636 \\
* *\end{array}$ & $\begin{array}{l}-.213^{*} \\
*\end{array}$ & $\begin{array}{l}-.292 \\
* *\end{array}$ & $\begin{array}{l}.136 \\
* *\end{array}$ & $\begin{array}{l}-.096 \\
* *\end{array}$ & $\begin{array}{l}-.238 \\
* *\end{array}$ & $\begin{array}{l}.210 \\
* *\end{array}$ & $\begin{array}{l}-.239 \\
* *\end{array}$ & $\begin{array}{l}-.244 \\
* *\end{array}$ & $\begin{array}{l}.276 \\
* *\end{array}$ & $-.247 *$ \\
\hline $\begin{array}{l}\text { FLCA } \\
\mathrm{S}\end{array}$ & & & & 1 & $\begin{array}{l}-.372 * \\
*\end{array}$ & $\begin{array}{l}-.425 \\
* *\end{array}$ & $\begin{array}{l}-.259 \\
* *\end{array}$ & $\begin{array}{l}-.214 \\
* *\end{array}$ & $\begin{array}{l}-.416 \\
* *\end{array}$ & $\begin{array}{l}-.299 \\
* *\end{array}$ & $\begin{array}{l}-.389 \\
* *\end{array}$ & $\begin{array}{l}-.362 \\
* *\end{array}$ & $\begin{array}{l}-.426 \\
* *\end{array}$ & $-.317 *$ \\
\hline $\begin{array}{l}\text { CSU } \\
\text { Q1 }\end{array}$ & & & & & 1 & $\begin{array}{l}.551 \\
* *\end{array}$ & $\begin{array}{l}.456 \\
* *\end{array}$ & $\begin{array}{l}.365 \\
* *\end{array}$ & $\begin{array}{l}.830 \\
* *\end{array}$ & $\begin{array}{l}.464 \\
* *\end{array}$ & $\begin{array}{l}.599 \\
* *\end{array}$ & $\begin{array}{l}.451 \\
* *\end{array}$ & $\begin{array}{l}.624 \\
* * *\end{array}$ & $.195^{*}$ \\
\hline $\begin{array}{l}\mathrm{CSU} \\
\mathrm{Q} 2 \\
\end{array}$ & & & & & & 1 & $\begin{array}{l}.422 \\
* * \\
\end{array}$ & $\begin{array}{l}.319 \\
* * \\
\end{array}$ & $\begin{array}{l}.719 \\
* * \\
\end{array}$ & $\begin{array}{l}.468 \\
* * \\
\end{array}$ & $\begin{array}{l}.540 \\
* * \\
\end{array}$ & $\begin{array}{l}.445 \\
* * \\
\end{array}$ & $\begin{array}{l}.589 \\
* * \\
\end{array}$ & $.238^{*}$ \\
\hline $\begin{array}{l}\text { CSU } \\
\text { Q3 }\end{array}$ & & & & & & & 1 & $\begin{array}{l}.349 \\
* * \\
\end{array}$ & $\begin{array}{l}.799 \\
* * \\
\end{array}$ & $\begin{array}{l}.480 \\
* *\end{array}$ & $\begin{array}{l}.536 \\
* * \\
\end{array}$ & $\begin{array}{l}.486 \\
* *\end{array}$ & $\begin{array}{l}.603 \\
* * \\
\end{array}$ & $.142^{*}$ \\
\hline $\begin{array}{l}\text { CSU } \\
\text { Q4 }\end{array}$ & & & & & & & & 1 & $\begin{array}{l}609 \\
* *\end{array}$ & $\begin{array}{l}.265 \\
* *\end{array}$ & $\begin{array}{l}.464 \\
* *\end{array}$ & $\begin{array}{l}.346 \\
* *\end{array}$ & $\begin{array}{l}.455 \\
* *\end{array}$ & .106 \\
\hline $\begin{array}{l}\text { CSU } \\
\text { Q }\end{array}$ & & & & & & & & & 1 & $\begin{array}{l}.571 \\
* *\end{array}$ & $\begin{array}{l}.715 \\
* *\end{array}$ & $\begin{array}{l}.582 \\
* *\end{array}$ & $\begin{array}{l}.763 \\
* *\end{array}$ & $.223^{*}$ \\
\hline $\begin{array}{l}\text { MSU } \\
\text { Q1 }\end{array}$ & & & & & & & & & & 1 & $\begin{array}{l}.471 \\
* *\end{array}$ & $\begin{array}{l}.454 \\
* *\end{array}$ & $\begin{array}{l}.706 \\
* *\end{array}$ & $.243^{*}$ \\
\hline $\begin{array}{l}\text { MSU } \\
\text { Q2 }\end{array}$ & & & & & & & & & & & 1 & $\begin{array}{l}.659 \\
* *\end{array}$ & $\begin{array}{l}.925 \\
* *\end{array}$ & $.153^{*}$ \\
\hline $\begin{array}{l}\text { MSU } \\
\text { Q3 }\end{array}$ & & & & & & & & & & & & 1 & $\begin{array}{l}.824 \\
* *\end{array}$ & $.181^{*}$ \\
\hline $\begin{array}{l}\text { MSU } \\
Q\end{array}$ & & & & & & & & & & & & & 1 & $.216^{*}$ \\
\hline $\begin{array}{l}\text { Perfor } \\
\text { mance }\end{array}$ & & & & & & & & & & & & & & 1 \\
\hline
\end{tabular}

As noted in Table 3, the FLCAS and its subscales were all significantly inversely correlated with the CSUQ and the MSUQ and their subscales, with coefficients ranging from -.096 to -.426 $(\mathrm{p}<.01)$. Namely, a respondent who reported to fear being negatively evaluated more, be more apprehensive of communication and tests, tended to use less all categories of cognitive and metacognitive strategies. Meanwhile, the CSUQ and its subscales were all significantly positively related to the MSUQ and its subscales, with a coefficient range of .265 to .763 ( $p<.01$ ). Evidently, a more frequent user of cognitive strategies of all kinds preferred to deploy metacognitive strategies more often as well. Finally, all the FLCAS scales were significantly negatively related to the students' performance in English, with a coefficient range of -.247 to -.317 ( $\mathrm{p}<.05$ ); while all the CSUQ and MSUQ scales except the CSUQ4 were significantly positively correlated with the latter, with coefficients ranging from .142 to .243 ( $p<.05$ ). That is, an anxious student was more inclined to perform poorly in English, while a more frequent user of cognitive or metacognitive strategies tended to perform better in English, as discovered in Purpura (1998).

\section{Regression Analyses}

The results of the correlational analyses discussed previously show numerous bivariate relationships, which failed to indicate the influence of one variable on another. Better clues were provided by multiple regression analyses. A stepwise method was employed in forming regression models. Altogether three models were resulted with the change in $\mathrm{R}^{2}$ being all significant: .001 for model 1 (FLCAS) $(\mathrm{p}=.000)$, .024 for model 2 (FLCAS, MSUQ1) $(\mathrm{p}=.000)$, and .005 for model 3 (FLCAS, MSUQ1, FLCAS1) ( $\mathrm{p}=.027)$. The results are shown in Table 4, which reports coefficients from the regression models, as well as their levels of significance.

TABLE 4:

REGRESSION COEFFICIENTS AND SIGNIFICANCE

\begin{tabular}{|l|l|l|l|l|}
\hline & & FLCAS & MSUQ1 & FLCAS1 \\
\hline \multirow{3}{*}{$\begin{array}{l}\text { Performance in } \\
\text { English }\end{array}$} & $\beta$ & -.436 & .155 & .180 \\
\cline { 2 - 5 } & $\mathrm{t}$ & -5.294 & 4.81 & 2.221 \\
\cline { 2 - 5 } & $\mathrm{p}$ & .000 & .000 & .027 \\
\cline { 2 - 5 } & $\mathrm{VIF}$ & 7.229 & 1.112 & 6.971 \\
\hline
\end{tabular}

As can be seen, all the coefficients were statistically significant at the .000 level except the FLCAS1 which was at the .027 level. Among the three included variables, the FLCAS was the most powerful predictor $(\beta=-.436, t=-5.294)$, followed by the MSUQ1 $(\beta=.155, t=4.81)$, and the FLCAS1 $(\beta=.180, t=2.221)$. The MSUQ1 and the FLCAS1 were positive predictors, while the FLCAS was a negative one. Contrary to the results of correlation analyses presented in Table 3, the FLCAS1 became a positive contributor to the students' performance in English, as revealed in Liu and Zhang (2011). This might be that anxiety negatively affected students' performance in English when working alone, but 
might become a positive factor when interacting with other variables, as discussed in Liu and Zhang (2011). Thus, a conclusion can be drawn that such factors as anxiety and metacognitive strategies yielded certain impact on the students' performance in English, which is further supported by the structural equation modeling of the variables shown in Figure 1.

\section{E. The Structural Model of the Measured Variables and Performance}

The statistical analyses of the data previously discussed indicate that the data satisfied the statistical assumptions of structural equation modeling (SEM). In specifying a general model of the relationships between reported degree of the measured variables and the students' performance in English for the sample, we argued for a three-factor model of foreign language classroom anxiety (FLCAS), a four-factor model of cognitive strategy use (CSUQ), and a three-factor model of metacognitive strategy use (MSUQ), as detailed in previous sections.

Of the numerous models tested, the baseline model of the measured variables and the students' performance, presented in Figure 1, seemed to fit the data well from both a statistical and substantive perspective. The model produced a CFI of .96 , a Chi-square of $204.07(\mathrm{p}=.000)$, and a RMSEA of .07 , implying a fairly good representation of the sample data. All the estimates (standardized) in the model were substantively plausible and statistically significant at the .000 level.

As shown in the structural model, classroom anxiety (-.49) showed a significant, negative effect, while the CSUQ (1.29) and the MSUQ (.96) exerted a significant, positive effect on the students' performance in English. Concerning the effect of the measured variables on one another, anxiety exhibited an interactive effect of -.53 with the CSUQ and -.4 with the MSUQ respectively; and the MSUQ produced a significant interactive effect of .96 with the CSUQ. All these results are largely consistent with those of correlation and regression analyses expounded previously, which attests to our hypothesis that anxiety and strategy use interact with each other to affect students' performance in English.

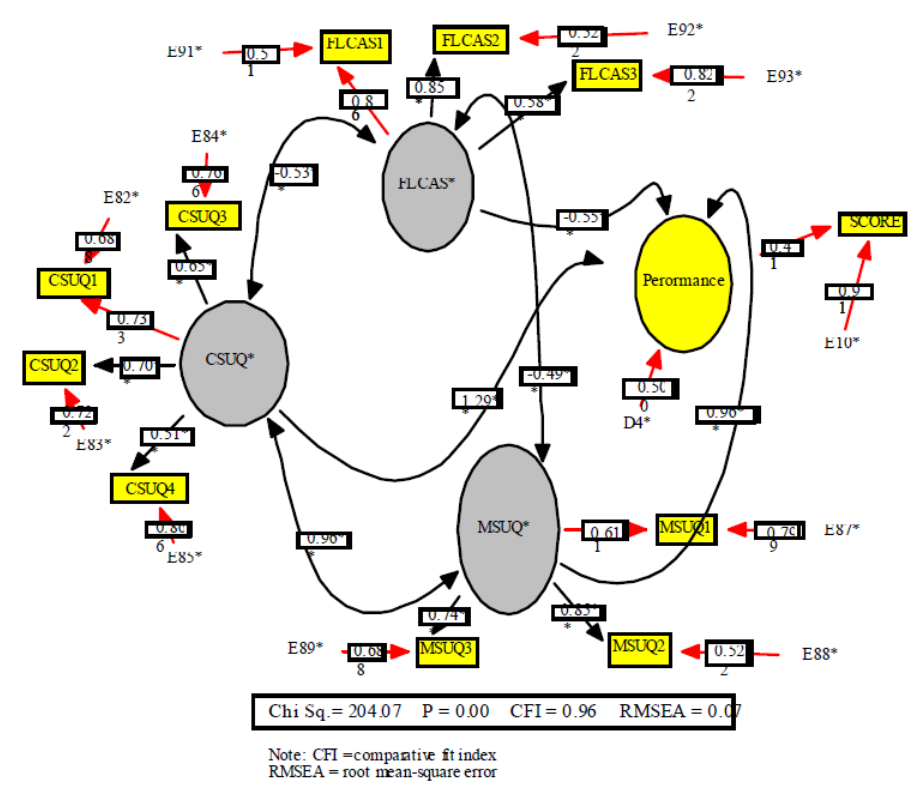

Figure 1: SEM of the Measured Variables and Performance

\section{CONCLUSIONS AND IMPLICATIONS}

Several conclusions can be drawn from the results of the present study on foreign language anxiety, cognitive and metacognitive strategy use and the students' performance in English. First, statistical analyses show that approximately a third of the respondents felt anxious in English class, feared being negatively evaluated, and were apprehensive about both speaking and tests. Second, the participants reported a medium use of the cognitive strategies of receiving and sending messages and analyzing and reasoning, but a low use of the strategies of practicing and creating structure for input and output. Likewise, they reported a medium use of all the categories of metacognitive strategies. Correlation and regression, as well as the SEM analyses, reveal that foreign language classroom anxiety, cognitive strategy use and metacognitive strategy use were all significantly correlated with one another, which again interactively affected the students' performance in English. For example, a respondent who reported to fear being negatively evaluated more tended to use less all categories of cognitive and metacognitive strategies and perform worse in English. Meanwhile, a more frequent user of cognitive strategies of all kinds preferred to deploy metacognitive strategies more often as well and was more inclined to perform better in English.

Since anxiety acted as a negative predictor of the students' performance in English when functioning alone, reducing students' anxiety may be important to enhance their learning outcomes, as discussed in a number of studies (Horwitz et 
al., 1986; Liu, 2006, 2007; Liu \& Zhang, 2010, 2011; Young, 1991). Meanwhile, it is worth noting that anxiety might exert a positive effect on the students' performance in English when interacting with other variables, as found in the present study. This suggests the multi-functions of anxiety in English learning, as reported in Liu and Zhang (2011). Therefore, it is necessary for both EFL teachers and learners to be prudent when dealing with anxiety in the teaching and learning of English. Instead of trying hard to create a relaxing environment, a certain degree of anxiety should be maintained on certain occasions to keep the students alert in English learning, as suggested by Liu and Zhang (2011).

Meanwhile, since both cognitive and metacognitive strategy use was evidenced to produce a significantly positive effect on the students' performance in English, it is worth trying to help students become (more) aware of the existence and importance of strategies to improve their use of the strategies. As Yang (1996) discovered, the students were able to "to improve the use of their learning strategies through awareness-raising in group interviews and informal strategy instruction" (1996, P. 204). Hence, it is beneficial to enhance FL/SL learners' awareness of strategy use through formal and informal instruction, since good awareness of metacognitive strategies is characteristic of good learners.

\section{ACKNOWLEDGEMENT}

The present study was sponsored by Asia Research Center in Tsinghua University in 2010.

\section{REFERENCES}

[1] Abraham, R. G., \& Vann, R. J. (1987). Strategies of two language learners: a case study. In A. Werden \& J. Rubin (Eds.), Learner strategies in language learning (85-102). London: Prentice Hall International.

[2] Argaman, O., \& Abu-Rabia, S. (2002). The influence of language anxiety on English reading and writing tasks among native Hebrew speakers. Language, Culture and Curriculum, 15, 143-160.

[3] Bailey, K. M. (1983). Competitiveness and anxiety in adult second language learning: looking at and through the dairy studies. In H. W. Seliger \& M. H. Long (Eds.), Classroom oriented research in second language acquisition (pp. 67-103). Rowley, Mass.: Newbury House Publishers, Inc.

[4] Bremner, S. (1999). Language learning strategies and language proficiency: investigating the relationship in Hong Kong. The Canadian Modern Language Review, 55, 496-514.

[5] Chamot, A. U., \& El-Dinary, P. B. (1999). Children's learning strategies in language immersion classrooms. The Modern Language Journal, 83, 319-338.

[6] Chamot, A. U., \& Küpper, L. (1989). Learning strategies in foreign language instruction. Foreign Language Annals, 22, $13-24$.

[7] Chen, H. (2002). College students' English learning anxiety and their coping styles. Southwest Normal University, unpublished M. A. dissertation.

[8] Cheng, Y., Horwitz, E. K., \& Schallert, D. L. (1999). Language anxiety: differentiating writing and speaking components. Language Learning, 49, 417-446.

[9] Ehrman, M. E., \& Oxford, R. L. (1995). Cognition plus: correlates of language learning success. The Modern Language Journal, 79, 67-89.

[10] Gardner, R. C., \& MacIntyre, P. D. (1992). Integrative motivation, induced anxiety, and language learning in a controlled environment. Studies in Second Language Acquisition, 14, 197-214.

[11] Grainger, P. R. (1997). Language-learning strategies for learners of Japanese: investigating ethnicity. Foreign Language Annals, 30, 378-385.

[12] Gregersen, T., \& Horwitz, E. K. (2002). Language learning and perfectionism: anxious and non-anxious language learners' reactions to their own oral performance. The Modern Language Journal, 86, 562-570.

[13] Gu, Y., \& Johnson, R. K. (1996). Vocabulary learning strategies and language learning outcomes. Language Learning, 46, 643-679.

[14] Horwitz, E. K. (2001). Language anxiety and achievement. Annual Review of Applied Linguistics, 21, 112-126.

[15] Horwitz, E. K., Horwitz, M., \& Cope, J. (1986). Foreign language classroom anxiety. The Modern Language Journal, 2 , 125-132.

[16] Liu, M. (2006). Anxiety in Chinese EFL students at different proficiency levels. System, 34, 301-316.

[17] Liu, M. (2007). Anxiety in oral English classrooms: a case study in China. Indonesian Journal of English Language Teaching, 3, 119-137.

[18] Liu, M., \& Jackson, J. (2008). An exploration of Chinese EFL learners' unwillingness to communicate and foreign language anxiety. The Modern Language Journal, 92, 71-86.

[19] Liu, M., \& Zhang, W. (2010). Affective and cognitive factors and foreign language achievement. B.C., Victoria: Traffold Publishing.

[20] Liu, M., \& Zhang, W. (2011). An exploration of Chinese EFL learners' foreign language anxiety, personality and self-esteem. Journal of Applied Linguistics, upcoming.

[21] Naiman, N., Frø̋hlich, M., Stern, H. H., \& Todesco, A. (1978). The good language learner. Research in Education Series, 7. Ontario Institute for Studies in Education.

[22] O'Malley, J. M., \& Chamot, A. U. (1990). Learning strategies in language acquisition. Cambridge: Cambridge University Press.

[23] O’Malley, J. M., Chamot, A. U., Stewner-Manzanares, Kupper, L., \& Russo, R. P. (1985). Learning strategies used by beginning and intermediate ESL students. Language Learning, 35, 21-46.

[24] Oxford, R. L. (1989). Use of language learning strategies: a synthesis of studies with implications for strategy training. System, $17,235-247$.

[25] Oxford, R. L. (1990). Language learning strategies: what every teacher should know. New York: Newbury House/Harper \& 
Row.

[26] Oxford, R. L., \& Nyikos, M. (1989). Variables affecting choice of language learning strategies by university students. Modern Language Journal, 73, 291-300.

[27] Phillips, E. M. (1992). The effects of language anxiety on students' oral test performance and attitudes. The Modern Language Journal, 76, 14-26.

[28] Purpura, J. E. (1997). An analysis of the relationships between test takers' cognitive and metacognitive strategy use and second language test performance. Language Learning, 47, 289-325.

[29] Purpura, J. E. (1998). Investigating the effects of strategy use and second language test performance with high- and low-ability test takers: a structural equation modeling approach. Language Testing, 15, 333-379.

[30] Rubin, J. (1975). What the 'good language learner' can teach us. TESOL Quarterly, 9, 41-51.

[31] Saito, Y., Horwitz, E. K., \& Garza, T. J. (1999). Foreign language reading anxiety. The Modern Language Journal, 83, $202-218$.

[32] Skehan, P. (1989). Individual differences in second language learning. London: Edward Arnold.

[33] Vandergrift, L. (1996). Listening strategies of core French high school students. The Canadian Modern Language Review, 52, 200-223.

[34] Vandergrift, L. (1997). The comprehension strategies of second language (French) listeners. Foreign Language Annals, 30, 387-409.

[35] Vandergrift, L. (2003). Orchestrating strategy use: toward a model of the skilled second language listener. Language Learning, $53,463-496$.

[36] Wang, C. (2003). Report of the FLCAS in college students. Journal of Psychology Science, 26, 281-284.

[37] Wang, D. (2007). How ESL learners with different proficiency levels handle unfamiliar vocabulary in reading. Indonesian Journal of English Language Teaching, 3, 72-98.

[38] Wen, Q. (1995). Differences in strategy use between successful and unsuccessful learners. Foreign Language Teaching and Research, 3, 61-66.

[39] Wen, Q. (1996). Structure, characteristics and monitor of the English learning strategy use system. Foreign Language Research, $1,56-60$.

[40] Yan, J. X., \& Horwitz, E. K. (2008). Learners' perceptions of how anxiety interacts with personal and instructional factors to influence their achievement in English: a qualitative analysis of EFL learners in China. Language Learning, 58, 151-183.

[41] Yang, N. (1996). Effective awareness-raising in language learning strategy instruction. In R. L. Oxford (Ed.), Language learning strategies around the world: cross-cultural perspectives (pp. 205-210). Manoa: University of Hawaii Press.

[42] Young, D. J. (1991). Creating a low-anxiety classroom environment: what does language anxiety research suggest? The Modern Language Journal, 75, 426-439.

[43] Zhang, W., \& Liu, M. (2008). Investigating cognitive and metacognitive strategy use during an English proficiency test. Indonesian Journal of English Language Teaching, 2, 122-139.

Zhongshe Lu is professor of English at the Department of Foreign Languages \& Literatures, Tsinghua University, China. Her major research interests include EFL teaching and learning, stylistics, and pedagogy.

Meihua Liu is associate professor of English at the Department of Foreign Languages \& Literatures, Tsinghua University, China. Her research interests mainly include EFL teaching and learning in the Chinese context, individual differences, anxiety and reticence, and EFL writing. 